\title{
Correlation between Positron Annihilation and Gas Diffusion Properties of Various Rubbery Polymers
}

\author{
Ken-ichi OKamoto, ${ }^{\dagger}$ Kazuhiro TanaKa, Mikio Katsube, \\ Hidetoshi Kita, Osamu SueoKa, ${ }^{*}$ and Yasuo Ito** \\ Department of Advanced Materials Science and Engineering, Faculty of Engineering, \\ Yamaguchi University, Ube, Yamaguchi 755, Japan \\ * Department of Applied Science, Faculty of Engineering, Yamaguchi University, \\ Yamaguchi 755, Japan \\ ** Research Center for Nuclear Science and Technology, The University of Tokyo, \\ Tokaimura, Ibaraki 319-11, Japan
}

(Received August 21, 1992)

\begin{abstract}
Diffusion coefficients $D$ for $\mathrm{CO}_{2}$ and $\mathrm{CH}_{4}$, their activation energies, $E_{\mathrm{D}}$, and lifetime and intensity of ortho-positronium $(o-\mathrm{Ps}), \tau_{3}$ and $I_{3}$ respectively, were measured for nine polymers at temperatures $T$ from glass transition temperature $T_{\mathrm{g}}$ up to $T_{\mathrm{g}}+70 \mathrm{~K}$. For semicrystalline polymers, $D$ and $I_{3}$ are corrected to give those in $100 \%$ amorphous samples, $D_{\text {a }}$ and $I_{3, \mathrm{a}}$, respectively. Average size of free volume holes probed by $o-\mathrm{Ps}, v_{\mathrm{h}, \mathrm{Ps}}$, is evaluated from $\tau_{3}$ using an empirical equation. According to the free volume model of diffusion, correlations between $\log \left(D_{\mathrm{a}} / T\right)$ and fractional free volume $f$ and between $E_{\mathrm{D}} / R T$ and $T f^{-2}(\mathrm{~d} f / \mathrm{d} T)$ are tested, using WLF fractional free volume $f_{\mathrm{WLF}}, v_{\mathrm{h}, \mathrm{Ps}} I_{3}$, and $v_{\mathrm{h}, \mathrm{Ps}}$ for $f$. The correlations are better for $v_{\mathrm{h}, \mathrm{Ps}}$ than for $v_{\mathrm{h}, \mathrm{Ps}_{\mathrm{s}}} I_{3}$. There is no correlation for $f_{\mathrm{WLF}}$. The volume fraction of free volume holes larger than the effective size of the penetrants, $V_{\mathrm{F}, \mathrm{dif}}$, are evaluated by a proposed model from $v_{\mathrm{h}, \mathrm{Ps}}$ and volume fraction of 'free space,' $V_{F}$, estimated by the method of van Kreveran and Bondi. The correlations are better for $V_{\mathrm{F}, \text { dif }}$ than for $V_{\mathrm{F}}$ and also for $v_{\mathrm{h}, \mathrm{Ps}}$. The apparent good correlations for $v_{\mathrm{h}, \mathrm{Ps}}$ are ascribed to the correlation of it with $V_{\mathrm{F}, \mathrm{dif}}$.
\end{abstract}

KEY WORDS Diffusion Coefficient / Rubbery Polymer / Free Volume / Positron Annihilation / ortho-Positronium / Carbon Dioxide / Free Volume Distribution /

Diffusion of penetrant molecules in polymers is a subject of great importance from the standpoint of membrane separation. Diffusion of penetrants in rubbery polymers is often interpreted by free volume theory. ${ }^{1-3}$ According to Fujita's formulation, ${ }^{1}$ the diffusion coefficient, $D_{0}$, at zero penetrant concentration is given by

$$
D_{0}=A_{\mathrm{d}} R T \exp \left(-B_{\mathrm{d}} / f\right)
$$

where $A_{\mathrm{d}}$ and $B_{\mathrm{d}}$ are the parameters dependent on penetrant molecular size and shape, $R$ is the gas constant, $T$ temperature, and $f$ fractional free volume. The fractional free volume is generally expressed by

$$
f=f_{\mathrm{g}}+\left(\alpha_{1}-\alpha_{\mathrm{g}}\right)\left(T-T_{\mathrm{g}}\right)
$$

where $f_{\mathrm{g}}$ is the fractional free volume at the glass-transition temperature $T_{\mathrm{g}}$, and $\alpha_{1}$ and $\alpha_{\mathrm{g}}$ are the thermal expansion coefficients above and below $T_{\mathrm{g}}$, respectively. Williams-LandelFerry (WLF) fractional free volume derived from viscosity theories, ${ }^{4,5} f_{\mathrm{WLF}}$, in which $f_{\mathrm{g}}$ is taken as 0.025 , is often used. Free volume in a rubbery polymer is generally considered to be composed of a spectrum of cavities

\footnotetext{
† To whom correspondence should be addressed.
} 
produced spontaneously by density fluctuations, namely, free volume elements (or holes). A portion of the free volume distribution involved in diffusion, which depends on the size of penetrant molecules, is not necessarily identical with that in viscosity. ${ }^{3}$

Positron annihilation (PA) in polymers has recently attracted much interest because PA is expected to bring forth information about their microstructure. ${ }^{6}$ PA lifetime spectra of polymers have a long-lived component which is attributed to ortho-positronium (o-Ps) formed and annihilated in amorphous regions. The lifetime of the long-lived component, $\tau_{3}$, is considered to be a good measure of the size of the micro-vacancies where $o$-Ps is trapped. The intensity of the long-lived component, $I_{3}$, is sometimes considered to be a measure of the number of such microvacancies. However, it is not mature to correlate $I_{3}$ with the number of such vacancies.

The micro-vacancies seen by $o$-Ps in rubbery polymers are presumed to be free volume holes large enough to accommodate $o$-Ps. Thus, free volume holes with the effective diameter larger than $c a .0 .4 \mathrm{~nm}$ are expected to be probed by $o$-Ps. This portion of the free volume distribution is close to that involved in the diffusion of gases such as $\mathrm{CO}_{2}$ and $\mathrm{CH}_{4}$. Therefore, it is interesting to compare the PA properties of rubbery polymers with gas transport properties.

Volkov et al. compared gas sorption and diffusion with PA properties for some rubbery polymers at room temperature. ${ }^{7,8}$ They claimed the following; (1) $\tau_{3} I_{3}$ is smaller for polymers having higher $T_{\mathrm{g}}$ and approaches zero when $T_{\mathrm{g}}$ is the experimental temperature (room temperature), suggesting that the free volume measured by the PA method is related mainly to the segmental mobility; (2) Logarithms of $D$ and of the solubility coefficient $S$ are closely correlated with $\left(\tau_{3} I_{3}\right)^{-1}$ and $\tau_{3}{ }^{-1}$, respectively. However, most of the rubbery polymers investigated by Volkov et al. have $T_{\mathrm{g}}$ values lower than $200 \mathrm{~K}$, and the
PA data for these polymers measured at room temperature are considered to originate not from the free volume holes in equilibrium controlling diffusion process but from Ps bubbles.

In the previous paper, ${ }^{9}$ we investigated PA properties of several polymers over wide temperature ranges above and below $T_{\mathrm{g}}$, and confirmed that the PA data measured at temperatures not much above $T_{\mathrm{g}}$ reflect the properties of free volume holes in equilibrium state rather than those of Ps bubbles. We also discussed the fraction of free volume holes probed by $o$-Ps and proposed a method to evaluate it from the PA data.

In this study, gas transport properties and PA properties have been examined for various rubbery polymers at temperatures not much above $T_{\mathrm{g}}$ to investigate how clearly diffusion coefficients for gases are correlated with the PA properties such as the volume fraction of free volume holes probed by $o$-Ps.

\section{EXPERIMENTAL}

The samples used in this study are as follows; low-density polyethylene (PE), 1,2polybutadiene (1,2-PB), poly(4-methylpentene (P4MP-C), poly(ethylene terephtalate) (PET), poly(vinyl acetate) (PVAC), poly(styrene) (PS), poly(methyl acrylate) (PMA), poly(buthyl methacrylate) (PBMA), and polyimide (6FDA-DAH PI) prepared from 2,2-Bis(3,4dicarboxyphenyl)hexafluoropropane dianhydride (6FDA) and 1,6-diaminohexane (DAH). The additive-free films of PE, P4MP-C, and PET were supplied from Ube Industries Ltd., Mitsui Petrochemical Industries Ltd., and Mitsubishi Plastics Ltd., respectively. P4MP-C is a copolymer of 4-methylpentene-1 with a small content of $\alpha$-olefine $\left(C_{18}\right.$ component $)$. Amorphous PET films (Diafoil) were heattreated at $408 \mathrm{~K}$ for $12 \mathrm{~h}$ in vacuo. 1,2-PB supplied from Japan Synthetic Rubber Ltd. was purified by repeated reprecipitations (toluene/methanol). Films of 1,2-PB, PVAC, 
PS, PMA, and PBMA were cast from their benzene solutions onto glass plates, and dried at $323 \mathrm{~K}$ ( $300 \mathrm{~K}$ for PMA) for $20 \mathrm{~h}$ in vacuo. ${ }^{9}$ 6FDA-DAH PI was prepared by the method described elsewhere ${ }^{10}$ and its films were cast from the dichloromethane solutions and dried at $373 \mathrm{~K}$ for $20 \mathrm{~h}$ in vacuo. Characterization of the films were carried out by the methods described in the previous paper. ${ }^{9}$

Gas sorption and transport experiments were carried out by the methods described elsewhere. ${ }^{10,11}$ The vacuum time-lag method was used to measure permeability coefficient $P$ and diffusion time-lag $\theta$. A dual-volume type sorption cell was used to measure solubility coefficient $S$. The $P$ and $S$ were measured for $\mathrm{CO}_{2}$ and $\mathrm{CH}_{4}$ at $1 \mathrm{~atm}$ and at temperatures from $T_{\mathrm{g}}$ up to $T_{\mathrm{g}}+70 \mathrm{~K}$. Diffusion coefficient $D$ was calculated from either $D=P / S$ or $D=l^{2} /(6 \theta)$ where $l$ is film thickness.

The PA lifetime measurements were carried out at the Inter-University Laboratory for the Common Use of JAERI facilities. ${ }^{12}$ The details are described in the previous papers. ${ }^{9,13}$ Each spectrum, having more than one million total count, was analyzed into three lifetime components using the computer program PATFIT $^{14}$

\section{RESULTS AND DISCUSSION}

Characterization results of the polymer films are listed in Table I. The amorphous fraction $\phi_{\mathrm{a}}$ were determined from the X-ray diffraction patterns and the densities $\rho$. The details have been described in the previous paper. ${ }^{9}$ Fraction of 'free space' $V_{F}$ refers to the ratio of the so-called 'expansion volume' 15 to the observed volume and was calculated by

$$
V_{\mathrm{F}}=\left(V_{\mathrm{T}}-V_{0}\right) / V_{\mathrm{T}}
$$

where $V_{\mathrm{T}}$ is the molar volume at temperature $T$ and $V_{0}$ is the volume occupied by the molecules at $0 \mathrm{~K}$ per mole of repeat unit of the polymer. $V_{\mathrm{T}}$ was calculated from the observed value at $298 \mathrm{~K}$ using $\alpha_{\mathrm{g}}$ and $\alpha_{1}$. $V_{0}$ was estimated to be 1.3 times $^{15}$ the van der Waals volume calculated by the group contribution method of Bondi. ${ }^{16}$

The average volume of the free volume holes probed by $o$-Ps, $v_{\mathrm{h}, \mathrm{Ps}}\left[=(4 / 3) \pi R^{3}\right]$, was calculated by the following equation between $\tau_{3}$ and the average radius $R$ of microvacancies. ${ }^{17,18}$

$$
\tau_{3}=(1 / 2)\left[1-\left(R / R_{0}\right)+(1 / 2 \pi) \sin \left(2 \Delta R / R_{0}\right)\right]^{-1}
$$

$$
R_{0}=R+\Delta R, \quad \Delta R=0.166 \mathrm{~nm}
$$

\begin{tabular}{|c|c|c|c|c|c|c|}
\hline \multirow{2}{*}{ Polymers } & \multirow{2}{*}{$\begin{array}{c}T_{\mathrm{g}} \\
\mathrm{K}\end{array}$} & \multirow{2}{*}{$\frac{\rho}{\mathrm{g} \mathrm{cm}^{-1}}$} & \multirow{2}{*}{$\begin{array}{c}\phi_{\mathrm{a}} \\
-\end{array}$} & $\alpha_{\mathrm{g}}$ & $\alpha_{1}$ & \multirow{2}{*}{$\begin{array}{l}V_{\mathrm{F}} \\
-\end{array}$} \\
\hline & & & & \multicolumn{2}{|c|}{$10^{-4} \mathrm{~K}^{-1}$} & \\
\hline 1,2-PB & 249 & 0.900 & 0.85 & 1.93 & 6.5 & 0.200 \\
\hline $\mathrm{PE}$ & 251 & 0.910 & 0.63 & 2.8 & 7.5 & 0.192 \\
\hline PMA & 280 & 1.209 & 1.0 & 2.7 & 5.6 & 0.159 \\
\hline P4MP-C & 295 & 0.835 & 0.65 & 3.71 & 7.38 & 0.209 \\
\hline PBMA & 307 & 1.051 & 1.0 & 4.02 & 6.45 & 0.164 \\
\hline PVAC & 304 & 1.190 & 1.0 & 1.71 & 5.06 & 0.176 \\
\hline PET & 361 & 1.376 & 0.67 & 2.47 & 6.20 & 0.149 \\
\hline PS & 377 & 1.045 & 1.0 & 2.11 & 5.57 & 0.180 \\
\hline 6FDA-DAH & 397 & 1.424 & 1.0 & 2 & $5^{b}$ & 0.137 \\
\hline
\end{tabular}

Table I. Characterization results of polymer films ${ }^{\mathrm{a}}$

a $\rho$ and $V_{\mathrm{F}}$ are at $298 \mathrm{~K}$.

b The $\alpha_{1}$ value of 6 FDA-DAH PI was assumed to be $5 \times 10^{-4} \mathrm{~K}^{-1}$ because it could not be measured by means of the thermomechanical analysis. 
Table II. Diffusion coefficients $D$ and activation energies $E_{\mathrm{D}}$ for $\mathrm{CO}_{2}$ and $\mathrm{CH}_{4}$ in rubbery polymers ${ }^{\mathrm{a}}$

\begin{tabular}{|c|c|c|c|c|c|c|}
\hline \multirow{2}{*}{ Polymer } & \multirow{2}{*}{$\begin{array}{c}l \\
\mu \mathrm{m}\end{array}$} & \multirow{2}{*}{$\frac{T}{\mathrm{~K}}$} & \multicolumn{2}{|c|}{$\mathrm{CO}_{2}$} & \multicolumn{2}{|c|}{$\mathrm{CH}_{4}$} \\
\hline & & & $D$ & $E_{\mathrm{D}}$ & $D$ & $E_{\mathrm{D}}$ \\
\hline \multirow[t]{2}{*}{ 1,2-PB } & 166 & 293 & 49 & 31 & 15.3 & 38 \\
\hline & & 308 & 91 & & 33 & \\
\hline \multirow[t]{3}{*}{ PE } & 47 & 303 & 58 & 45 & 35 & 51 \\
\hline & & 313 & 107 & & 86 & \\
\hline & & 323 & 180 & & 119 & \\
\hline \multirow[t]{4}{*}{ PMA* } & 40 & 283 & 0.47 & 62 & - & - \\
\hline & & 298 & 2.2 & & 1.64 & \\
\hline & & 303 & 3.1 & & - & \\
\hline & & 308 & 3.7 & & 3.0 & \\
\hline \multirow[t]{3}{*}{ P4MP-C } & 54 & 303 & - & & $43^{*}$ & (28) \\
\hline & & 308 & 104 & 30 & 78 & \\
\hline & & 323 & 180 & & 109 & \\
\hline \multirow[t]{2}{*}{ PBMA } & 77 & 308 & 31 & 34 & 25 & 38 \\
\hline & & 323 & 57 & & 49 & \\
\hline \multirow[t]{2}{*}{ PVAC } & 38 & 313 & 1.2 & 70 & 0.32 & 92 \\
\hline & & 323 & 2.7 & & 0.96 & \\
\hline \multirow[t]{3}{*}{ PET $^{*}$} & 54 & 363 & 2.2 & 68 & 0.84 & 75 \\
\hline & & 378 & 5.3 & & 2.4 & \\
\hline & & 393 & 12 & & 5.6 & \\
\hline \multirow[t]{3}{*}{ PS* } & 220 & 378 & 93 & 38 & 39 & 52 \\
\hline & & 388 & 117 & & 53 & \\
\hline & & 403 & 190 & & 108 & \\
\hline 6FDA-DAH & 64 & 403 & 8.1 & - & 2.6 & - \\
\hline
\end{tabular}

a $D$ is in $10^{-8} \mathrm{~cm}^{2} \mathrm{~s}^{-1}$, and $E_{\mathrm{D}}$ is in $\mathrm{kJ} \mathrm{mol}^{-1}$. The $D$ data for the polymers asterisked were determined from the time lag. The $l$ values are for typical films.

The long-lived component is assingned to $o$-Ps annihilating in the amorphous region. It has been found for semicrystalline polymers that $I_{3}$ linearly depends on $\phi_{\mathrm{a}}$ but $\tau_{3}$ does not. ${ }^{19} I_{3}$ values for the semicrystalline polymers were, therefore, corrected to give those in $100 \%$ amorphous samples, $I_{3, \mathrm{a}}$, as

$$
I_{3, \mathrm{a}}=I_{3} / \phi_{\mathrm{a}}
$$

The data of $D$ are summarized in Table II. The $D$ for $\mathrm{CO}_{2}$ and $\mathrm{CH}_{4}$ in the rubbery polymers used here is practically independent of feed pressure below $5 \mathrm{~atm}$. Therefore, the $D$ values measured at $1 \mathrm{~atm}$ can be regarded as the $D_{0}$ values. The $D$ values for the semicrystalline polymers were corrected to give those in $100 \%$ amorphous samples, $D_{\mathrm{a}}$, as

$$
D=D_{\mathrm{a}} / \tau \beta
$$

where $\tau$ is the tortosity factor, and $\beta$ is the chain immobilization factor. The $\tau$ was approximated as $\tau=\phi_{\mathrm{a}}{ }^{-1} \cdot{ }^{20}$ The $\beta$ was approximated as $1.0-1.1$ for $\mathrm{CO}_{2}$ and $1.0-1.4$ for $\mathrm{CH}_{4}$, depending on $\phi_{\mathrm{a}} \cdot{ }^{21}$

\section{Correlation of $D_{\mathrm{a}}$ with WLF Fractional Free Volume}

A linear correlation between $\log \left(D_{\mathrm{a}} / T\right)$ and $f_{\mathrm{WLF}}^{-1}$ is predicted from eq 1 , provided that the parameters $A_{\mathrm{d}}$ and $B_{\mathrm{d}}$ for a given penetrant does not much vary from polymer to polymer. Figure 1 shows plots of $\log \left(D_{\mathrm{a}} / T\right)$ versus $f_{\mathrm{WLF}}^{-1}$ for $\mathrm{CO}_{2}$ in the rubbery polymers. From the viewpoint of WLF free volume, the glass transition is described as an isofree volume state. As can be seen in Figure 1 , the values of $D_{\mathrm{a}} / T$ near $T_{\mathrm{g}}$ vary by 150 times and no linear relation between $\log \left(D_{a} / T\right)$ and 


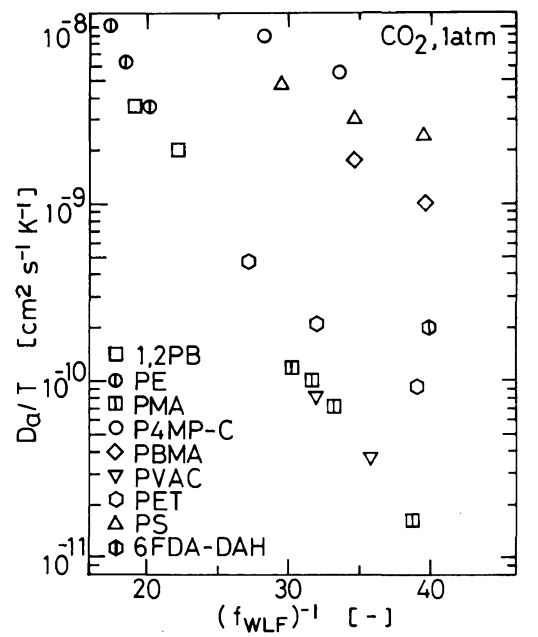

Figure 1. Plots of $\log \left(D_{\mathrm{a}} / T\right)$ versus $f_{\mathrm{WLF}}^{-1}$ for rubbery polymers.

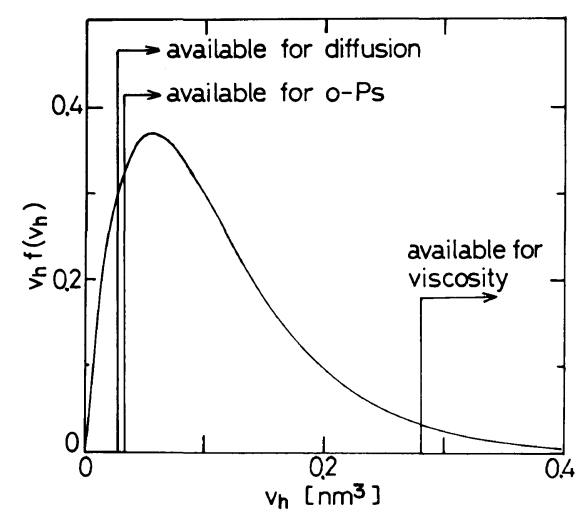

Figure 2. Typical example of the distribution function of fractional free volume.

$f_{\mathrm{WLF}}{ }^{-1}$ is observed. The situation is the same for $\mathrm{CH}_{4}$. The large variation in $D / T_{\mathrm{g}}$ for $\mathrm{Ar}$ was also reported for other polymers. ${ }^{22,23}$ This result might be explained by considering the difference in the segmental mobility. However, it would be important to take the size distribution of the fluctuating free volume holes into account.

The distribution function of the size of free volume holes, $f\left(v_{\mathrm{h}}\right)$, for rubbery polymers is described by

$$
f\left(v_{\mathrm{h}}\right)=\left(1 /\left\langle v_{\mathrm{h}}\right\rangle\right) \exp \left(-v_{\mathrm{h}} /\left\langle v_{\mathrm{h}}\right\rangle\right)
$$

where $\left\langle v_{\mathrm{h}}\right\rangle$ is a mean size of free volume holes. ${ }^{24}$ Figure 2 illustrates the distribution function of fractional free volume, $v_{\mathrm{h}} f\left(v_{\mathrm{h}}\right)$. Only the free volume holes large enough for a chain segment of a given polymer to be accommodated can contribute to the viscosity of the polymer and consequently WLF fractional free volume involves only this portion of free volume distribution. On the other hand, the free volume holes large enough for a penetrant molecule to pass through can contribute to the diffusion of the penetrant. The effective diameters for diffusion of $\mathrm{CO}_{2}$ and $\mathrm{CH}_{4}$ are 0.35 and $0.38 \mathrm{~nm}$, respectively. ${ }^{25,26}$ Therefore, free volume holes larger than $v_{\mathrm{h}}$ of about $0.029 \mathrm{~nm}^{3}$ are presumed to contribute to the diffusion of these penetrants. The volume fraction of such free volume holes, $V_{\mathrm{F}, \mathrm{dif}}$ is much larger than $f_{\mathrm{WLF}}$ and rather close to the volume fraction of free volume holes probed by $o$-Ps, $V_{\mathrm{F}, \mathrm{Ps}}$. This should be the reason that there is no correlation between $\log \left(D_{\mathrm{a}} / T\right)$ and $f_{\mathrm{WLF}}{ }^{-1}$.

Correlation of $D$ with $v_{\mathrm{h}, \mathrm{Ps}} I_{3, \mathrm{a}}$ and $v_{\mathrm{h}, \mathrm{Ps}}$

From the above discussion it is suggested that either $V_{\mathrm{F} \text {,dif }}$ or $V_{\mathrm{F}, \mathrm{Ps}}$ should be used for $f$ in eq 1 instead of $f_{\mathrm{WLF}}$. However, $V_{\mathrm{F}, \mathrm{dif}}$ can not be evaluated directly without any assumption. $V_{\mathrm{F}, \mathrm{Ps}}$ is given by the product of $v_{\mathrm{h}, \mathrm{Ps}}$ and the concentration of free volume holes probed by $o$-Ps, $C_{\mathrm{h}, \mathrm{Ps}}$. Volkov et al. presumed that $\tau_{3} I_{3}$ is proportional to the fractional free volume and found a clear correlation between $\log D$ and $\left(\tau_{3} I_{3}\right)^{-1}$ for five rubbery polymers at room temperature. ${ }^{7,8}$ Therefore, presuming that $v_{\mathrm{h}, \mathrm{Ps}} I_{3, \mathrm{a}}$ is a direct measure of $f$, we first examine how clearly $\log \left(D_{\mathrm{a}} / T\right)$ is correlated to $v_{\mathrm{h}, \mathrm{Ps}} I_{3, \mathrm{a}}$ for the rubbery polymers at temperatures not much above $T_{\mathrm{g}}$. Figure 3 shows plots of $\log \left(D_{\mathrm{a}} / T\right)$ for $\mathrm{CO}_{2}$ versus $\left(v_{\mathrm{h}, \mathrm{Ps}} I_{3, \mathrm{a}}\right)^{-1}$. There is a correlation between them except for 6FDA-DAH PI. The data point $(D / T=$ $2 \times 10^{-10}$ and $\left.\left(v_{\mathrm{h}, \mathrm{Ps}} I_{3, \mathrm{a}}\right)^{-1}=137\right)$ for $6 \mathrm{FDA}$ DAH PI is very apart from the correlation line. From the slope of the correlation 


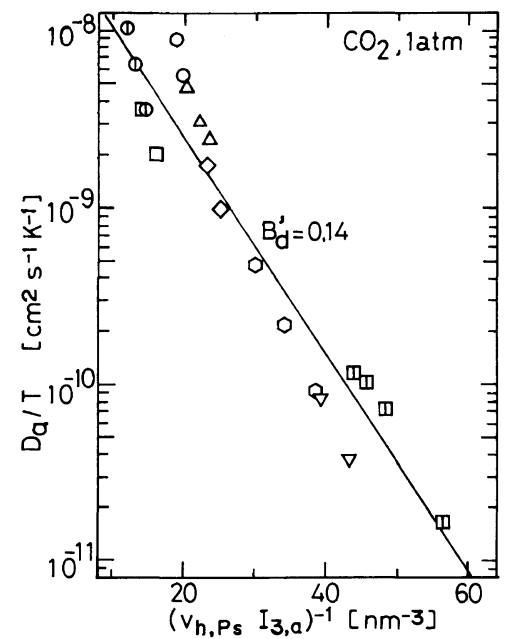

Figure 3. Plots of $\log \left(D_{\mathrm{a}} / T\right)$ versus $\left(v_{\mathrm{h}, \mathrm{Ps}} I_{3, \mathrm{a}}\right)^{-1}$ for rubbery polymers. The symbols are as in Figure 1.

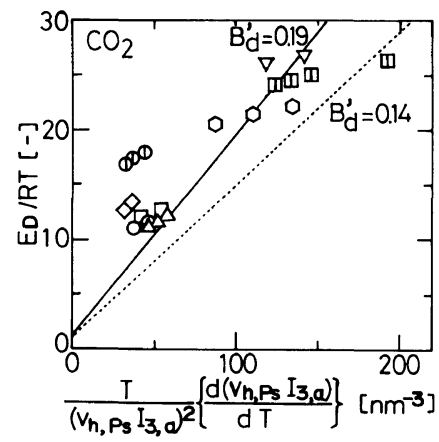

Figure 4. Plots of $E_{\mathrm{D}} / R T$ versus $T\left(v_{\mathrm{h}, \mathrm{Ps}} I_{3, \mathrm{a}}\right)^{-2} \mathrm{~d}\left(v_{\mathrm{h}, \mathrm{Ps}} I_{3, \mathrm{a}}\right) /$ $\mathrm{d} T$ for rubbery polymers. The symbols are as in Figure 1 .

line, $B_{\mathrm{d}}{ }^{\prime}\left(=B_{\mathrm{d}} v_{\mathrm{h}, \mathrm{Ps}} I_{3, \mathrm{a}} / f\right)$ is evaluated to be $0.14 \mathrm{~nm}^{3}$. The correlation is much clearer for $\mathrm{CO}_{2}$ than for $\mathrm{CH}_{4}$.

The temperature dependence of the diffusion coefficients is considered to be of Arrhenius type with the apparent activation energies $E_{\mathrm{D}}$ listed in Table II. From the viewpoint of the free volume model of diffusion, $E_{\mathrm{D}}$ is described by

$$
E_{\mathrm{D}} / R T=1+B_{\mathrm{d}} T f^{-2}(\mathrm{~d} f / \mathrm{d} T)
$$

where $B_{\mathrm{d}}$ is the same parameter as in eq 1 . According to eq $8, E_{\mathrm{D}} / R T$ for $\mathrm{CO}_{2}$ are plotted against $T\left(v_{\mathrm{h}, \mathrm{Ps}} I_{3, \mathrm{a}}\right)^{-2} \mathrm{~d}\left(v_{\mathrm{h}, \mathbf{P s}} I_{3}\right) / \mathrm{d} T$ in Figure 4 .

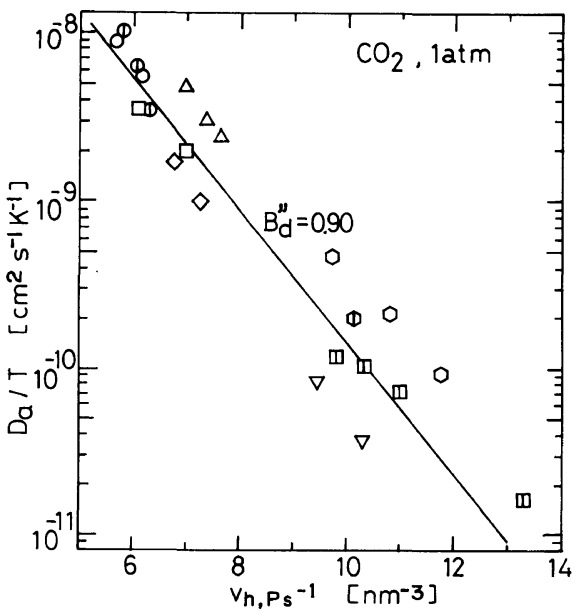

Figure 5. Plots of $\log \left(D_{\mathrm{a}} / T\right)$ versus $v_{\mathrm{h}, \mathrm{Ps}}{ }^{-1}$ for rubbery polymers. The symbols are as in Figure 1.

There is a rough correlation between them. However, the $B_{\mathrm{d}}{ }^{\prime}$ value, $0.19 \mathrm{~nm}^{3}$, evaluated from the correlation line is much different from the value $\left(0.14 \mathrm{~nm}^{3}\right)$ evaluated from the correlation between $\log \left(D_{\mathrm{a}} / T\right)$ and $\left(v_{\mathrm{h}, \mathrm{Ps}} I_{3, \mathrm{a}}\right)^{-1}$.

In a previous paper, we found that $\log D$ for $\mathrm{CO}_{2}$ and $\mathrm{CH}_{4}$ in a series of polyimides at $308 \mathrm{~K}$ was correlated more clearly to $v_{\mathrm{h}, \mathrm{Ps}}$ than to $v_{\mathrm{h}, \mathrm{Ps}} I_{3, \mathrm{a} \cdot}{ }^{13}$ Recently, we have proposed a method to evaluate $C_{\mathrm{h}, \mathrm{Ps}}$ and $V_{\mathrm{F}, \mathrm{Ps}}$ from $\tau_{3}$ and $V_{\mathrm{F}}$ on some assumptions, and predicted that there is a correlation between $V_{\mathrm{F}, \mathrm{Ps}}$ and $v_{\mathrm{h}, \mathrm{Ps}}$ but not between $C_{\mathrm{h}, \mathrm{Ps}}$ and $I_{3}$ for the rubbery polymers. ${ }^{9}$ Then, we next examine how clearly $\log \left(D_{\mathrm{a}} / T\right)$ is correlated to $v_{\mathrm{h}, \mathbf{P s}}{ }^{-1}$. As shown in Figure 5, there is a correlation between $\log \left(D_{\mathrm{a}} / T\right)$ and $v_{\mathrm{h}, \mathrm{Ps}}{ }^{-1}$, although the data for larger $v_{\mathrm{h}, \mathrm{Ps}}{ }^{-1}$ are rather scattered. The data point for 6FDA-DAH PI is almost on the correlation line. As shown in Figure 6 , there is a rough linear correlation between $E_{\mathrm{D}} / R T$ and $T v_{\mathrm{h}, \mathrm{Ps}}{ }^{-2} \mathrm{~d} v_{\mathrm{h}, \mathrm{Ps}} / \mathrm{d} T$ with the slope equal to the $B_{\mathrm{d}}{ }^{\prime \prime}\left(=B_{\mathrm{d}} v_{\mathrm{h}, \mathrm{Ps}} / f\right)$ value, $0.90 \mathrm{~nm}^{3}$ evaluated from the correlation between $\log \left(D_{\mathrm{a}} / T\right)$ and $v_{\mathrm{h}, \mathrm{Ps}}{ }^{-1}$.

These results reveal that diffusion of gaseous penetrants in the rubbery polymers at temperatures not much above $T_{\mathrm{g}}$ is well described 
by the free volume model using $v_{\mathrm{h}, \mathrm{Ps}}$ rather than $v_{\mathrm{h}, \mathrm{Ps}} I_{3, \mathrm{a}}$ for $f$ in eq 1 and 8 . This seems to be because $v_{\mathrm{h}, \mathrm{Ps}}$ is correlated to $V_{\mathrm{F}, \mathrm{Ps}}$ and, as a result, to $V_{\mathrm{F}, \mathrm{dif}} \cdot{ }^{9}$

\section{Correlation of $D$ with $V_{\mathrm{F}, \mathrm{dif}}$}

Now, we apply the method used for evaluation of $V_{\mathrm{F}, \mathrm{Ps}}{ }^{9}$ to evaluate $V_{\mathrm{F}, \mathrm{dif}}$. Free volume holes of rubbery polymers have the size disribution of exponential type (eq 7). The volume fraction of total free volume holes is reasonably assumed to be equal to $V_{\mathrm{F}}$ calculated by eq 4 .

$$
V_{\mathrm{F}}=\int_{0}^{\infty} C_{\mathrm{h}, \mathrm{t}} f\left(v_{\mathrm{h}}\right) v_{\mathrm{h}} \mathrm{d} v_{\mathrm{h}}=\left\langle v_{\mathrm{h}}\right\rangle C_{\mathrm{h}, \mathrm{t}}
$$

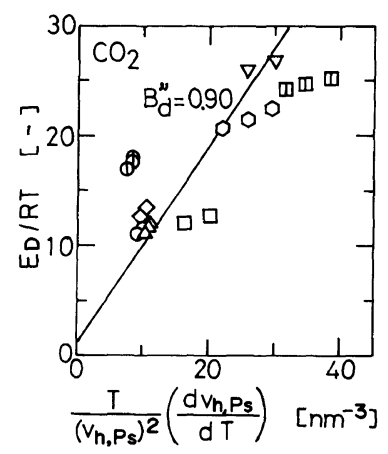

Figure 6. Plots of $E_{\mathrm{D}} / R T$ versus $T v_{\mathrm{h}, \mathrm{Ps}}{ }^{-2} \mathrm{~d} v_{\mathrm{h}, \mathrm{Ps}} / \mathrm{d} T$ for rubbery polymers. The symbols are as in Figure 1. where $C_{\mathrm{h}, \mathrm{t}}$ is the concentration of total free volume holes. It is not clear whether $o$-Ps is trapped in all the free volume holes larger than the critical size $a=0.033 \mathrm{~nm}^{3}$ with equal probability. It is probable that $o$-Ps is trapped in a larger free volume holes with a larger probability. Therefore, taking the function $g\left(v_{\mathrm{h}}\right)$ which describes the ease of trapping 0 Ps into consideration, average size, volume fraction, and concentration of free volume holes probed by $o-\mathrm{Ps}, v_{\mathrm{h}, \mathrm{Ps}}, V_{\mathrm{F}, \mathrm{Ps}}$, and $C_{\mathrm{h}, \mathrm{Ps}}$, respectively, are described by eq 10,11 , and 12 .

$$
\begin{aligned}
& v_{\mathrm{h}, \mathbf{P s}}=\int_{a}^{\infty} v_{\mathrm{h}} f\left(v_{\mathrm{h}}\right) g\left(v_{\mathrm{h}}\right) \mathrm{d} v_{\mathrm{h}} / \int_{a}^{\infty} f\left(v_{\mathrm{h}}\right) g\left(v_{\mathrm{h}}\right) \mathrm{d} v_{\mathrm{h}} \\
& V_{\mathrm{F}, \mathbf{P s}}=C_{\mathrm{h}, \mathrm{t}} \int_{a}^{\infty} v_{\mathrm{h}} f\left(v_{\mathrm{h}}\right) g\left(v_{\mathrm{h}}\right) \mathrm{d} v_{\mathrm{h}}=v_{\mathrm{h}, \mathbf{P s}} C_{\mathrm{h}, \mathbf{P s}} \\
& C_{\mathrm{h}, \mathbf{P s}}=C_{\mathrm{h}, \mathrm{t}} \int_{a}^{\infty} f\left(v_{\mathrm{h}}\right) g\left(v_{\mathrm{h}}\right) \mathrm{d} v_{\mathrm{h}}
\end{aligned}
$$

As $g\left(v_{\mathrm{h}}\right)$, we tentatively use the following function.

$$
g\left(v_{\mathrm{h}}\right)=1-\exp \left[-b\left(v_{\mathrm{h}}-a\right)\right]
$$

\begin{tabular}{|c|c|c|c|c|c|c|c|c|}
\hline \multirow{2}{*}{ Polymer } & $\tau_{3}$ & $I_{3}$ & $v_{\mathrm{h}, \mathrm{Ps}}$ & $\left\langle v_{\mathbf{h}}\right\rangle$ & $C_{\mathrm{h} . \mathrm{t}}$ & $V_{\mathrm{F}}$ & $V_{\mathrm{F}, \mathbf{P s}}$ & $V_{\mathbf{F}, \text { dif }}$ \\
\hline & ns & $\%$ & $\mathrm{~nm}^{3}$ & $\mathrm{~nm}^{3}$ & $\mathrm{~nm}^{-3}$ & - & - & - \\
\hline 1,2-PB & 1.96 & 33.0 & 0.093 & 0.038 & 4.61 & 0.175 & 0.076 & 0.144 \\
\hline $1,2-\mathrm{PB}^{\mathrm{b}}$ & 2.46 & 36.7 & 0.143 & 0.079 & 2.51 & 0.198 & 0.144 & 0.188 \\
\hline$P E^{c}$ & 2.62 & 25.7 & 0.159 & 0.093 & 2.10 & 0.196 & 0.152 & 0.188 \\
\hline PMA & 1.72 & 23.5 & 0.072 & 0.023 & 6.58 & 0.151 & 0.034 & 0.097 \\
\hline P4MP-C & 2.55 & 20.0 & 0.152 & 0.087 & 2.39 & 0.207 & 0.157 & 0.198 \\
\hline PBMA & 2.42 & 29.4 & 0.138 & 0.075 & 2.24 & 0.167 & 0.118 & 0.158 \\
\hline PVAC & 1.95 & 23.4 & 0.092 & 0.037 & 4.73 & 0.177 & 0.076 & 0.145 \\
\hline PET & 1.86 & 20.4 & 0.084 & 0.032 & 5.13 & 0.162 & 0.058 & 0.125 \\
\hline PS & 2.34 & 32.2 & 0.130 & 0.068 & 2.86 & 0.194 & 0.131 & 0.181 \\
\hline 6FDA-DAH & 1.96 & 6.4 & 0.093 & 0.038 & 4.06 & 0.154 & 0.067 & 0.127 \\
\hline
\end{tabular}

For an assumed value of $b$ in eq $13,\left\langle v_{\mathrm{h}}\right\rangle$ of a rubbery polymer at temperature $T$ is determined from the observed value of $v_{\mathrm{h}, \mathrm{Ps}}$ by

Table III. Free volume properties of the polymers at $T_{\mathrm{g}}$ evaluated from the PA data by the model ${ }^{\mathrm{a}}$

a $\left\langle v_{\mathrm{h}}\right\rangle, C_{\mathrm{h}, \mathrm{t}}, V_{\mathrm{F}, \mathbf{P s}}$, and $V_{\mathrm{F}, \mathrm{dif}}$ were calculated for $b=20$ in $g\left(v_{\mathrm{h}}\right)$.

b At $\left(T_{\mathrm{g}}+44\right) \mathrm{K}$.

c At $\left(T_{\mathrm{g}}+52\right) \mathrm{K}$. 


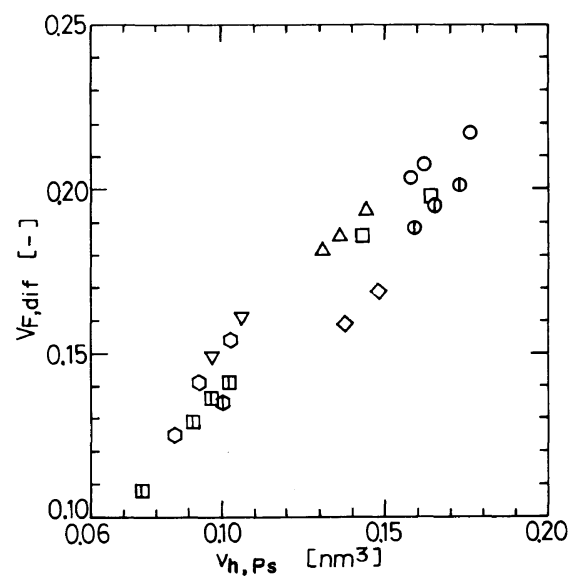

Figure 7. Plots of $V_{\mathrm{F}, \mathrm{dif}}$ calculated for $b=20$ in $g\left(v_{\mathrm{h}}\right)$ versus $v_{\mathrm{h}, \mathrm{Ps}}$ for rubbery polymers. The symbols are as in Figure 1.

eq 10 , then $C_{\mathrm{h}, \mathrm{t}}$ is determined from the value of $V_{\mathrm{F}}$ by eq 9 , and finally $C_{\mathrm{h}, \mathrm{Ps}}$ and $V_{\mathrm{F}, \mathrm{Ps}}$ are calculated by eq 11 and 12 . The results calculated for the assumed values of $b$ from 20 to infinite are not much different each other. In a first approximation, we presume that all the free volume holes larger than $v_{\mathrm{h}}=0.029 \mathrm{~nm}^{3}$ can equally contribute to the diffusion of $\mathrm{CO}_{2}$ and $\mathrm{CH}_{4}$, and then $V_{\mathrm{F}, \mathrm{dif}}$ is given by

$$
V_{\mathrm{F}, \mathrm{dif}}=C_{\mathrm{h}, \mathrm{t}} \int_{0.029}^{\infty} v_{\mathrm{h}} f\left(v_{\mathrm{h}}\right) \mathrm{d} v_{\mathrm{h}}
$$

Free volume properties of the polymers at $T_{\mathrm{g}}$ evaluated thus from the PA data are listed in Table III. Among the polymers investigated here, $\left\langle v_{\mathrm{h}}\right\rangle$ varies from $0.023 \mathrm{~nm}^{3}(0.35 \mathrm{~nm}$ in diameter) for PMA to $0.087 \mathrm{~nm}^{3}(0.55 \mathrm{~nm})$ for P4MP-C. For P4MP-C, the $\left\langle v_{\mathrm{h}}\right\rangle$ value is much larger than the effective size of the penetrants, $0.029 \mathrm{~nm}^{3}(0.38 \mathrm{~nm}$ in diameter $)$ and the $V_{\mathrm{F}, \mathrm{dif}}$ value is only $4 \%$ smaller than the $V_{\mathrm{F}}$ value. On the other hand, for PMA, the $\left\langle v_{\mathrm{h}}\right\rangle$ value is a little smaller than the effective size of the penetrants and the $V_{\mathrm{F}, \mathrm{dif}}$ value is only $64 \%$ as large as $V_{\mathrm{F}}$. Figure 7 shows plots of $V_{\mathrm{F}, \mathrm{dif}}$ versus $v_{\mathrm{h}, \mathrm{Ps}}$ for the rubbery polymers. There is a correlation

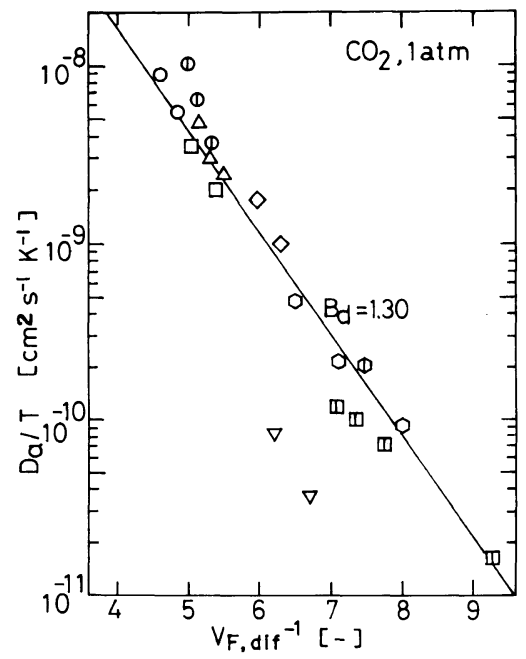

(a)

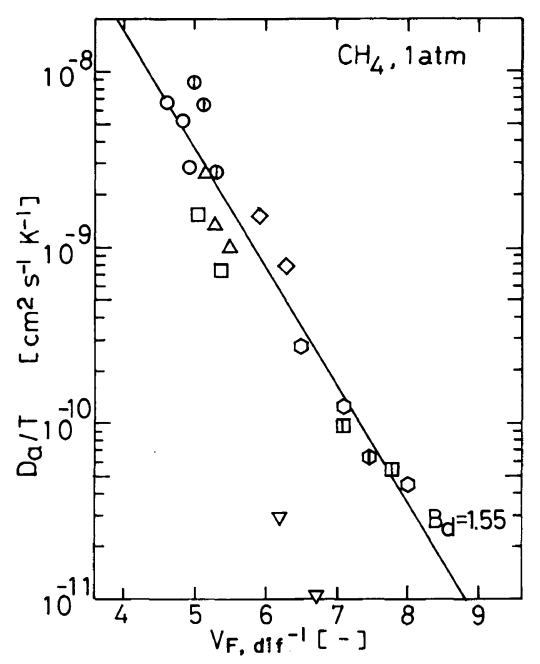

(b)

Figure 8. Plots of $\log \left(D_{\mathrm{a}} / T\right)$ versus $V_{\mathrm{F}, \mathrm{dif}}{ }^{-1}$ for rubbery polymers. The symbols are as in Figure 1.

between $V_{\mathrm{F}, \mathrm{dif}}$ and $v_{\mathrm{h}, \mathrm{Ps}}$; polymers with larger $v_{\mathrm{h}, \mathrm{Ps}}$ or $\left\langle v_{\mathrm{h}}\right\rangle$ have larger $V_{\mathrm{F}, \mathrm{dif}}$.

As shown in Figure 8, there are clear correlations between $\log \left(D_{\mathrm{a}} / T\right)$ and $V_{\mathrm{F}, \mathrm{dif}}$ for $\mathrm{CO}_{2}$ and $\mathrm{CH}_{4}$ in all the rubbery polymers investigated except for PVAC. As shown in Figure 9 , there is a rough correlation between $E_{\mathrm{D}} / R T$ and $T V_{\mathrm{F}, \mathrm{dif}}{ }^{-2}\left(\mathrm{~d} V_{\mathrm{F}, \mathrm{dif}} / \mathrm{d} T\right)$ with the slope equal to the $B_{\mathrm{d}}$ value (1.3) for $\mathrm{CO}_{2}$ 


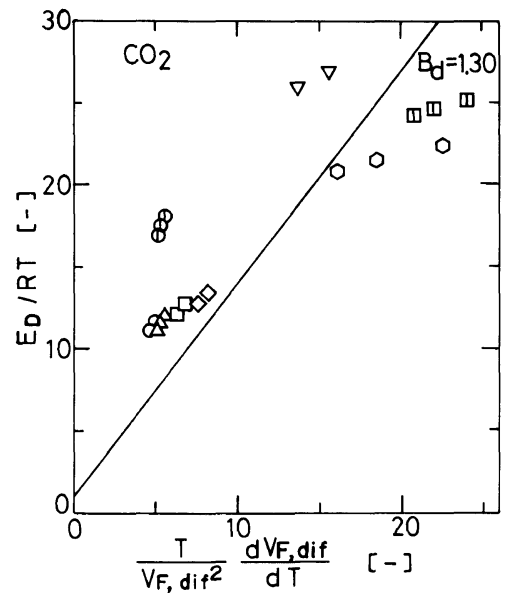

Figure 9. Plots of $E_{\mathrm{d}} / R T$ versus $T V_{\mathrm{F}, \mathrm{dif}}{ }^{-2} \mathrm{~d} V_{\mathrm{F}, \mathrm{dif}} / \mathrm{d} T$ for rubbery polymers. The symbols are as in Figure 1.

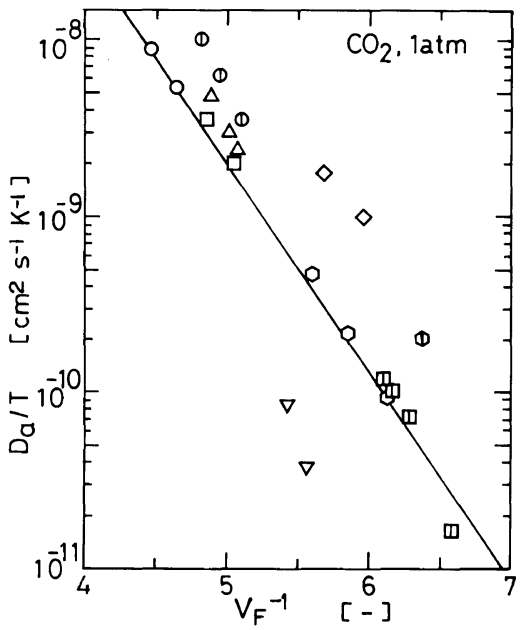

Figure 10. Plots of $\log \left(D_{\mathrm{a}} / T\right)$ versus $V_{\mathrm{F}}^{-1}$ for rubbery polymers. The symbols are as in Figure 1 .

evaluated from the correlation line in Figure 8. As shown in Figure $10, \log \left(D_{\mathrm{a}} / T\right)$ is correlated to $V_{\mathrm{F}}{ }^{-1}$ with somewhat large scattering. It is noteworthy that $D$ is correlated better with $V_{\mathrm{F} \text {,dif }}$ than with $V_{\mathrm{F}}$; the correlation is improved by taking the size distribution of free volume holes into account. In the present model, for the polymers having relatively large $V_{\mathrm{F}}$, the $V_{\mathrm{F} \text {,dif }}$ values are only slightly different from the $V_{\mathrm{F}}$ values, because the $\left\langle v_{\mathrm{h}}\right\rangle$ is much larger than the effective size of the penetrants. On the other hand, for the polymers having relatively small $V_{\mathrm{F}}$, the $V_{\mathrm{F}, \mathrm{dif}}$ values are fairly different from the $V_{\mathrm{F}}$ values, depending on the magnitude of $\left\langle v_{\mathrm{h}}\right\rangle$. The $\left\langle v_{\mathrm{h}}\right\rangle$ values of PBMA and 6FDA-DAH PI are larger than those for PET and PMA, respectively, and as a result the data points for the formers are upward away from the correlation line between $\log \left(D_{\mathrm{a}} / T\right)$ and $V_{\mathrm{F}}{ }^{-1}$. This is corrected in the plots of $\log \left(D_{\mathrm{a}} / T\right)$ versus $V_{\mathrm{F}, \mathrm{dif}}{ }^{-1}$, resulting in the better correlation.

The validity of the free volume properties evaluated by the present model crucially depends on the validity of the estimated value of the fractional volume of whole free volume holes. The best way to estimate this is believed to be the method developed by van Krevelen ${ }^{15}$ and used in present study. The limitation of the present model lies in this point. The data point of PVAC are far away from both the correlation lines of $\log \left(D_{\mathrm{a}} / T\right)$ with $V_{\mathrm{F}, \mathrm{dif}}{ }^{-1}$ and $V_{\mathrm{F}}{ }^{-1}$, of which the reason may lie in the validity of the estimated value of $V_{\mathrm{F}}$ of PVAC.

Acknowledgements. This work was supported by a Grand-in-Aid for Scientific Research (No. 03650729) from the Ministry of Education, Science, and Culture of Japan.

\section{REFERENCES}

1. H. Fujita, Forschr. Hochpolym. Forsch., 3, 1 (1961).

2. C. A. Kumins and T. K. Kwei, "Diffusion in Polymers," J. Krank and G.S. Park, Ed., Academic Press, New York, N.Y., 1968, Chapter 4.

3. H. L. Frish, P. Klempner, and T. K. Kwei, Macromolecules, 4, 237 (1971).

4. M. I. Williams, R. F. Landel, and J. D. Ferry, $J$. Am. Chem. Soc., 77, 3701 (1955).

5. R. N. Haward, J. Macromol. Sci., Rev. Macromol. Chem., c, 4, 191 (1970).

6. Y. C. Jean, "Positron and Positronium Chemistry," Y. C. Jean, Ed., World Scientific, New Jersey, 1990 p 1.

7. V. V. Volkov, A. V. Goldanskii, S. G. Durgayan, V. A. Onishchk, V. P. Shantorovich, and Yu. P. Yampolskii, Polym. Sci. USSR, 29, 217 (1987).

8. V. V. Volkov, Polym. J., 23, 457 (1991). 
9. K. Okamoto K. Tanaka, M. Katsube, H. Kita, and Y. Ito, Bull. Chem. Soc. Jpn., 66, 61 (1993).

10. K. Tanaka, H. Kita, and K. Okamoto, Polymer, 33, 585 (1992).

11. K. Tanaka, H. Kita, K. Okamoto, A. Nakamura, and Y. Kusuki, Polym. J., 21, 127 (1989).

12. T. Suzuki, Y. Ito, K. Endo, S. Fujita, Y. Masuda, and T. Egusa, Int. J. Appl. Radiat. Isot., 39, 53 (1988).

13. K. Tanaka, M. Katsube, K. Okamoto, H. Kita, S. Sueoka, and Y. Ito, Bull. Chem. Soc. Jpn., 65, 1891 (1992).

14. P. Kirkegaad, N. J. Pedersen, and M. Eldrup, PATFITT-88, Riso-M- 2740.

15. D. W. van Krevelen, "Properties of Polymers," Elsevier, Amsterudam, 1976, p 65.

16. A. Bondi, "Physical Properties of Molecular Crystals, Liquids, and Gases," Wiely, New York, N.Y., 1968, p 450.

17. S. T. Tao, J. Chem. Phys., 56, 5499 (1972).
18. M. Eldrup, D. Lightbody, and J. N. Sherwood, Chem. Phys., 63, 51 (1984).

19. H. Nakanishi and Y. C. Jean, J. Polym. Sci., 27, 1419 (1989).

20. A. S. Michaels, H. J. Bixler, and H. L. Fein, J. Appl. Phys., 35, 3165 (1964).

21. A. S. Michaels and H. J. Bixler, J. Polym. Sci., 10, 413 (1961).

22. V. T. Stannett, "Structual Order in Polymer," F. Ciardelli and P. Giusti, Ed., Pergamon Press, New York, N.Y., 1980, p 244.

23. K. Terada, K. Mizoguchi, and T. Hirose, J. Polym. Sci., Polym. Phys. Ed., 30, 539 (1992).

24. S. Trohalaki, L. C. DeBolt, J. E., Mark, and H. L. Frish, Macromolecules, 23, 813 (1990).

25. A. R. Berens and H. B. Hopfenberg, J. Membrance Sci., 10, 283 (1982).

26. K. Okamoto, K. Tanaka, H. Kita, M. Ishida, M. Kakimoto, and Y. Imai, Polym. J., 24, 451 (1992). 